\title{
Age and gender related prevalence of temporomandibular disorders in North Indian population
}

\author{
Akhilanand Chaurasia ${ }^{1, *}$, Ashish R. ${ }^{2}$, Gaurav Katheriya ${ }^{3}$ \\ ${ }^{1,2}$ Assistant Professor, ${ }^{3}$ Resident, Dept. of Oral Medicine \& Radiology, ${ }^{1,3}$ Faculty of Dental Sciences, King George's Medical \\ University, Lucknow, Uttar Pradesh, ${ }^{2}$ Government Medical College, Trivandrum, Kerala, India
}

*Corresponding Author:

Email: chaurasiaakhilanand49@gmail.com

\begin{abstract}
Aims: The present study is taken in account to determine the age and gender related prevalence of TMDs on the basis of signs and symptoms based on the RDC/TMD criteria.

Materials and Method: The present cross-sectional study was conducted in the Department of Oral Medicine and Radiology. A total of 1009 patients aged between 6 and 80 years with a mean age of $42.04 \pm 16.8$ years seeking dental treatment from January 2016 to June 2017 were included in the study. All the subjects were screened for TMDs signs and symptoms. The demographic data and the signs and symptoms of TMDs were recorded in respect to age and gender in designed structured questionnaire which were based on the RDC/TMD criteria.

Results: The association between signs and symptoms based on the RDC/TMD criteria and gender was evaluated in study population by Chi-Square test. The clicking sound and deviation of mandible on mouth opening is more prevalent in males than females and both are statistically significant $(\mathrm{P}<0.05)$.Crepitus and joint tenderness is more common in females. The joint tenderness in both sexes was highly significant $(\mathrm{P}<.001)$ However crepitus was statistically not significant $(\mathrm{P}>0.05)$. When signs and symptoms based on the RDC/TMD criteria was compared in age groups, it was found that clicking sound and pain on mouth opening is most prevalent in <18years of age groups however crepitus was more common in>65 years age group. All the three parameters were statistically significant $(\mathrm{P}<.001)$ in age groups. The joint tenderness was most common in 36 to 50 years group while Deviation of mandible on mouth opening was more prevalent in 51-65 years of age group.

Conclusion: There is strong association between sign and symptoms of the RDC/TMD criteria and age and gender of patient's i.e the clicking sound and deviation of mandible on mouth opening is more prevalent in males however crepitus and joint tenderness is more common in females. Clicking sound and pain on mouth opening is most prevalent in $<18$ years of age groups however crepitus was more common in $>65$ years age group.
\end{abstract}

Keywords: RDC/TMD criteria, Temporomandibular disorders, Crepitus, Joint tenderness, MPDS.

\section{Introduction}

The term "Temporomandibular disorders" (TMDs) encompasses a wide spectrum of signs and symptoms. There have been a lot of attempts to formulate a universally acceptable classification for categorization of this wide group of conditions. But each classification or category has some shortfall or the other. Classification has been attempted on the basis of anatomical changes, etiological factors and by some researchers on the basis of the frequency of the presenting signs and symptoms. There has always been a considerable overlap in any classification system. TMDs affect the articulation of the condyle with the glenoid fossa, masticatory muscles and the occlusion. There is a wide interplay between the above mentioned factors and a thorough investigation of all possible factors should be done before a final diagnosis of TMD is made. ${ }^{1}$

Scientific investigation of TMDs began in the early1950s. Earlier it has been suggested that the improper occlusion could influence masticator muscle functions. Later throughout the 1960s and 1970s, the emotional stress and occlusal conditions were considered as the major etiologic factors of functional disorders of the TMJDs. Further with increasing research, it is commonly accepted that TMJ derangement is of multifactorial origin and is best thought of as the result of a combination of occlusal, neurophysiologic and psychological factors. ${ }^{2}$ Patients with TMD usually suffer from muscle and/or joint pain on palpation and onmandibular movements, joint sounds and the mandibular range of motion may be limited. ${ }^{3}$ The multifactorial TMJD etiology is related to emotional tension, teeth loss, occlusal interferences, masticatory muscular dysfunction, postural deviation, internal and external changes in TMJ structure and the various associations of these factors. ${ }^{4}$

TMD can affect any patients regardless of age including children ${ }^{5}$ or gender with varying signs and symptoms. ${ }^{6}$ However due to the variation in symptoms among different patients and in the same patient at different times, the diagnosis of this clinical entity may be difficult. ${ }^{7}$ Epidemiological studies have estimated that approximately $50-75 \%$ of the population exhibit signs of TMDs. Internal derangement (36.8\%) may be subclinical and the patient might not try to relate this to an underlying jaw problem. In less than $15-20 \%$ of the patients, the signs changed into symptoms for which the patient will seek treatment. The frequency to seek treatment increases if the symptoms interfere with dayto-day activities. ${ }^{1}$ The prevalence of TMD is high in general population $40 \%$ to $60 \%{ }^{8}$ 
Now a day, with an increasing awareness and interest of the public towards oral health there is a need to provide attention towards the temporomandibular joint disorders. ${ }^{9}$ Temporomandibular Joint (TMJ) issues can lie dormant in a patient. While some patients are not aware of their condition, many realize that they are experiencing something that is not normal in the TMJ but do not understand its future consequences or even worse how to correct it. A sharp pain while eating or a loud click in the TMJ could be their warning call ${ }^{10}$. So there is a very much need to screen and scrutinize these patients and determine the prevalence of TMD in patients. This cross-sectional study was done to assess and evaluate the prevalence of signs and symptoms associated with Temporomandibular joint disorders as per RDC criteria. This prevalence study will be the milestone and a paradigm for the future diagnosis and treatment plan for temporomandibular disorders.

\section{Materials and Method}

The Research Diagnostic Criteria for Temporomandibular disorders (RDC/TMD) is defined as a collective term describing a group of conditions affecting either the temporomandibular joint (TMJ) or the masticatory musculature or both. The signs and symptoms of TMDs include pain in the masticatory musculature and/or joint which can radiate and refer, locking closed, open lock, inability to open fully, dislocation, noises like clicking and crepitus during joint movement, headache, tightness around the face in the morning and referred pain to the ear. Males and females of age from 6 years to 80 years were included in study. Patients whose third molars have been extracted, patients with a history of fracture of the TMJ and previous TMJ surgeries, non cooperative subjects, TMJ pathologies were excluded from study. The study was conducted from January 2016 to June 2017. The demographic data and the signs and symptoms of TMDs were recorded in respect to age and gender in designed structured questionnaire which were based on the RDC/TMD criteria.

\section{Statistical tools}

Categorical variables will be presented in number and percentage (\%). Qualitative variables will be compared using Chi-Square test /Fisher's exact test as appropriate. A p value of $<0.05$ will be considered statistically significant. The data will be entered in MS EXCEL spreadsheet and analysis will be done using Statistical Package for Social Sciences (SPSS) version 21.0.

\section{Results}

The study samples are selected randomly and consist of 1009 subjects aged between 6 to 80 years with a mean age of $42.04 \pm 16.8$ years (Table 1 ). The study population is divided in5 age groups. Majority of the study subjects belongs to 18 to 35 years of age group (22.5\%) (Table 2). The female subjects $(66.6 \%)$ dominated the study population than male (Table 3).The association between clicking sound and gender was evaluated in study population by Chi-Square test. The clicking sound was more prevalent in males $(47.2 \%)$ than females $(40.4 \%)$ and it was statistically significant $(\mathrm{P}<0.05)($ Table 4$)$. The crepitus in temporomandibular joint was more common in female $(26.6 \%)$ than male $(24.1 \%)$ and this relation was statistically not significant $(\mathrm{P}>0.05)$ (Table $5)$. The joint tenderness was found more in female $(8.1 \%)$ than male $(0.9 \%)$. The joint tenderness in both sexes was highly significant $(\mathrm{P}<.001)$ (Table 6). Deviation of mandible on mouth opening was more prevalent in male $(47.2 \%)$ than female $(37.8 \%)$ and it was statistically significant $(\mathrm{P}<.05)$ (Table 7$)$.

Table 1

\begin{tabular}{|c|c|c|c|c|c|}
\hline & N & Minimum & Maximum & Mean & Std. Deviation \\
\hline Age & 1009 & 6 & 80 & 42.04 & 16.868 \\
\hline
\end{tabular}

Table 2

\begin{tabular}{|l|c|c|}
\hline \multicolumn{1}{|c|}{ Gender } & Frequency & Percent \\
\hline Male & 337 & 33.4 \\
\hline Female & 672 & 66.6 \\
\hline Total & 1009 & 100.0 \\
\hline
\end{tabular}

Table 3

\begin{tabular}{|l|c|c|}
\hline \multicolumn{1}{|c|}{ Age Intervals } & Frequency & Percent \\
\hline Below 18yrs & 42 & 4.2 \\
\hline 18 to 35yrs & 407 & 40.3 \\
\hline 36 to 50yrs & 227 & 22.5 \\
\hline 51 to 65yrs & 219 & 21.7 \\
\hline More than 65yrs & 114 & 11.3 \\
\hline Total & 1009 & 100.0 \\
\hline
\end{tabular}


Table 4

\begin{tabular}{|c|c|c|c|c|}
\hline \multicolumn{2}{|c|}{} & \multicolumn{2}{c|}{ Gender } & \multirow{2}{*}{ Total } \\
\hline \multirow{2}{*}{$\begin{array}{c}\text { Clicking } \\
\text { sound }\end{array}$} & \multirow{2}{*}{ Yes } & Male & Female & \\
\cline { 2 - 5 } & \multirow{2}{*}{ No } & 151 & 277 & 430 \\
\cline { 3 - 5 } & $47.2 \%$ & $40.4 \%$ & $42.5 \%$ \\
\cline { 3 - 5 } & 169 & 412 & 581 \\
\hline \multicolumn{2}{|c|}{ Total } & $52.8 \%$ & $59.6 \%$ & $57.5 \%$ \\
\cline { 3 - 5 } & 320 & 689 & 1009 \\
\hline \multicolumn{2}{|c|}{} & $100.0 \%$ & $100.0 \%$ & $100.0 \%$ \\
\hline
\end{tabular}

Table 5

\begin{tabular}{|c|c|c|c|c|}
\hline \multicolumn{2}{|c|}{} & \multicolumn{2}{c|}{ Gender } & \multirow{2}{*}{ Total } \\
\hline \multirow{3}{*}{ Crepitus } & Male & Female & \\
\hline \multirow{3}{*}{} & \multirow{2}{*}{ Yes } & 77 & 184 & 261 \\
\cline { 3 - 5 } & \multirow{2}{*}{ No } & $24.1 \%$ & $26.6 \%$ & $25.8 \%$ \\
\cline { 3 - 5 } & & 243 & 505 & 748 \\
\cline { 3 - 5 } & $75.9 \%$ & $73.4 \%$ & $74.2 \%$ \\
\hline \multicolumn{2}{|c|}{ Total } & 320 & 691 & 1009 \\
\cline { 3 - 5 } & $100.0 \%$ & $100.0 \%$ & $100.0 \%$ \\
\hline
\end{tabular}

Table 6

\begin{tabular}{|c|c|c|c|c|}
\hline \multicolumn{2}{|c|}{} & \multicolumn{2}{c|}{ Gender } & \multirow{2}{*}{ Total } \\
\hline \multirow{3}{*}{$\begin{array}{c}\text { Joint } \\
\text { tenderness }\end{array}$} & \multirow{2}{*}{ Yes } & Male & Female & \\
\cline { 3 - 5 } & \multirow{2}{*}{ No } & 9 & 56 & 59 \\
\cline { 3 - 5 } & & 317 & $8.1 \%$ & $5.8 \%$ \\
\cline { 3 - 5 } & $99.1 \%$ & 933 & 950 \\
\hline \multicolumn{2}{|c|}{ Total } & 320 & 689 & $94.2 \%$ \\
\cline { 3 - 5 } & $100.0 \%$ & $100.0 \%$ & $100.0 \%$ \\
\hline
\end{tabular}

Table 7

\begin{tabular}{|l|c|c|c|c|}
\hline \multicolumn{2}{|c|}{} & \multicolumn{2}{c|}{ Gender } & \multirow{2}{*}{ Total } \\
\hline \multicolumn{2}{|c|}{} & Male & Female & \\
\hline $\begin{array}{l}\text { Deviation of } \\
\text { Mandible on } \\
\text { mouth } \\
\text { opening }\end{array}$ & \multirow{2}{*}{ Yes } & 151 & 261 & 412 \\
\cline { 3 - 5 } & \multirow{2}{*}{ Notal } & $47.2 \%$ & $37.8 \%$ & $40.8 \%$ \\
\hline & & 169 & 428 & 597 \\
\hline \multicolumn{2}{|c|}{ Tot. } & 320 & $62.2 \%$ & $59.2 \%$ \\
\cline { 3 - 5 } & $100.0 \%$ & $100.0 \%$ & $100.0 \%$ \\
\hline
\end{tabular}

All the study parameters were compared in age groups. It was found that clicking sound was most common in <18years of age group $(62.5 \%)$ followed by 18-35 years $(55.6 \%)$ (Table 8$)$. It was statistically significant $(\mathrm{P}<.001)$. The crepitus was most common in $>65$ years age group (58.6\%) followed by 51-65 years age group $(50.9 \%)$ and it was statistically significant $(\mathrm{P}<.001)$ (Table 9). The joint tenderness is most common in 36 to 50 years group $(5.7 \%)$ followed by
18-35 years $(5.6 \%)$ (Table 10). It was It was statistically non significant $(\mathrm{P}>.005)$. Deviation of mandible on mouth opening was more prevalent in 5165 years of age group $(49.4 \%)$ followed by $36-50 \mathrm{yrs}$ and it was statistically significant $(\mathrm{P}<.001)$ (Table.11). Pain on mouth opening is most prevalent in $<18$ yrs of age group followed by $36-50$ yrs of age. And it was statistically significant $(\mathrm{P}<.001)$ (Table 12). 
Table 8

\begin{tabular}{|c|c|c|c|c|c|c|c|}
\hline & \multicolumn{5}{|c|}{ Age Intervals } & \multirow[t]{2}{*}{ Total } \\
\hline & & $\begin{array}{l}\text { Below } \\
\text { 18yrs }\end{array}$ & $\begin{array}{l}18 \text { to } \\
35 y r s\end{array}$ & $\begin{array}{l}36 \text { to } \\
50 \mathrm{yrs}\end{array}$ & $\begin{array}{l}51 \text { to } \\
65 \mathrm{yrs}\end{array}$ & $\begin{array}{c}\text { More than } \\
65 \text { yrs }\end{array}$ & \\
\hline \multirow{4}{*}{$\begin{array}{l}\text { Clicking } \\
\text { sound }\end{array}$} & \multirow{2}{*}{ Yes } & 5 & 160 & 197 & 57 & 11 & 430 \\
\hline & & $62.5 \%$ & $55.6 \%$ & $47.0 \%$ & $21.3 \%$ & $37.9 \%$ & $42.5 \%$ \\
\hline & \multirow{2}{*}{ No } & 3 & 128 & 222 & 208 & 18 & 579 \\
\hline & & $37.5 \%$ & $44.4 \%$ & $53.0 \%$ & $78.7 \%$ & $62.1 \%$ & $57.5 \%$ \\
\hline \multirow{2}{*}{\multicolumn{2}{|c|}{ Total }} & 8 & 288 & 419 & 267 & 29 & 1009 \\
\hline & & $100.0 \%$ & $100.0 \%$ & $100.0 \%$ & $100.0 \%$ & $100.0 \%$ & $100.0 \%$ \\
\hline
\end{tabular}

Table 9

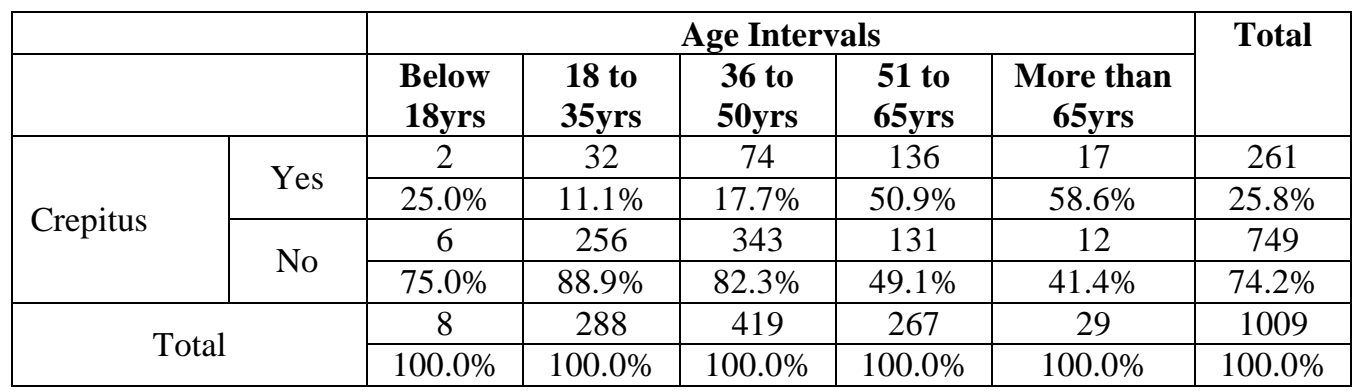

Table 10

\begin{tabular}{|c|c|c|c|c|c|c|c|}
\hline & \multicolumn{5}{|c|}{ Age Intervals } & \multirow[t]{2}{*}{ Total } \\
\hline & & $\begin{array}{l}\text { Below } \\
\text { 18yrs }\end{array}$ & $\begin{array}{l}18 \text { to } \\
35 y r s\end{array}$ & $\begin{array}{l}36 \text { to } \\
50 \mathrm{yrs}\end{array}$ & $\begin{array}{l}51 \text { to } \\
65 \mathrm{yrs}\end{array}$ & $\begin{array}{c}\text { More than } \\
65 \mathrm{yrs}\end{array}$ & \\
\hline \multirow{4}{*}{$\begin{array}{l}\text { Joint } \\
\text { tenderness }\end{array}$} & \multirow{2}{*}{ Yes } & 0 & 16 & 24 & 19 & 0 & 59 \\
\hline & & $.0 \%$ & $5.6 \%$ & $5.7 \%$ & $7.1 \%$ & $.0 \%$ & $5.8 \%$ \\
\hline & \multirow{2}{*}{ No } & 8 & 272 & 393 & 248 & 29 & 950 \\
\hline & & $100.0 \%$ & $94.4 \%$ & $94.3 \%$ & $92.9 \%$ & $100.0 \%$ & $94.2 \%$ \\
\hline \multirow{2}{*}{\multicolumn{2}{|c|}{ Total }} & 8 & 288 & 419 & 267 & 29 & 1009 \\
\hline & & $100.0 \%$ & $100.0 \%$ & $100.0 \%$ & $100.0 \%$ & $100.0 \%$ & $100.0 \%$ \\
\hline
\end{tabular}

Table 11

\begin{tabular}{|c|c|c|c|c|c|c|c|}
\hline & \multicolumn{5}{|c|}{ Age Intervals } & \multirow[t]{2}{*}{ Total } \\
\hline & & $\begin{array}{l}\text { Below } \\
\text { 18yrs }\end{array}$ & $\begin{array}{l}18 \text { to } \\
35 y r s\end{array}$ & $\begin{array}{l}36 \text { to } \\
50 y r s\end{array}$ & $\begin{array}{l}51 \text { to } \\
65 y r s\end{array}$ & $\begin{array}{c}\text { More than } \\
65 y r s\end{array}$ & \\
\hline \multirow{4}{*}{$\begin{array}{l}\text { Deviation of } \\
\text { Mandible on } \\
\text { mouth Opening }\end{array}$} & \multirow{2}{*}{ Yes } & 0 & 100 & 174 & 132 & 6 & 412 \\
\hline & & $.0 \%$ & $34.7 \%$ & $41.5 \%$ & $49.4 \%$ & $20.7 \%$ & $40.8 \%$ \\
\hline & \multirow{2}{*}{ No } & 8 & 188 & 243 & 135 & 23 & 597 \\
\hline & & $100.0 \%$ & $65.3 \%$ & $58.5 \%$ & $50.6 \%$ & $79.3 \%$ & $59.2 \%$ \\
\hline \multirow{2}{*}{\multicolumn{2}{|c|}{ Total }} & 8 & 288 & 419 & 267 & 29 & 1009 \\
\hline & & $100.0 \%$ & $100.0 \%$ & $100.0 \%$ & $100.0 \%$ & $100.0 \%$ & $100.0 \%$ \\
\hline
\end{tabular}

Table 12

\begin{tabular}{|c|c|c|c|c|c|c|c|}
\hline & \multicolumn{5}{|c|}{ Age Intervals } & \multirow[t]{2}{*}{ Total } \\
\hline & & $\begin{array}{l}\text { Below } \\
\text { 18yrs }\end{array}$ & $\begin{array}{l}18 \text { to } \\
\text { 35yrs }\end{array}$ & $\begin{array}{l}36 \text { to } \\
50 y r s\end{array}$ & $\begin{array}{l}51 \text { to } \\
65 y r s\end{array}$ & $\begin{array}{l}\text { More than } \\
\text { 65yrs }\end{array}$ & \\
\hline \multirow{4}{*}{$\begin{array}{l}\text { Pain on mouth } \\
\text { opening }\end{array}$} & \multirow[t]{2}{*}{ Yes } & 3 & 14 & 31 & 2 & 0 & 50 \\
\hline & & $37.5 \%$ & $4.9 \%$ & $7.4 \%$ & $.7 \%$ & $.0 \%$ & $4.9 \%$ \\
\hline & \multirow[t]{2}{*}{ No } & 5 & 274 & 384 & 265 & 29 & 959 \\
\hline & & $62.5 \%$ & $95.1 \%$ & $92.6 \%$ & $99.3 \%$ & $100.0 \%$ & $95.1 \%$ \\
\hline \multirow{2}{*}{\multicolumn{2}{|c|}{ Total }} & 8 & 288 & 419 & 267 & 29 & 1009 \\
\hline & & $100.0 \%$ & $100.0 \%$ & $100.0 \%$ & $100.0 \%$ & $100.0 \%$ & $100.0 \%$ \\
\hline
\end{tabular}


The MPDS was more prevalent in male (45.2\%) than female (28\%). Statistically this association was significant $(\mathrm{P}<0.05)$ (Table 13). However the osteoarthritis has high prevalence $(31.7 \%)$ in female than male $(25.2 \%)$ and it was statistically significant $(\mathrm{P}<0.05)$ (Table 14). Internal derangement in females $(40.3 \%)$ are more prevalent than males $(29.7 \%)$ (Table 15$)$ and this association are statistically significant $(\mathrm{P}<.001)$.

\section{Table 13}

\begin{tabular}{|l|c|c|c|c|}
\hline & & \multicolumn{2}{c|}{ Gender } & \multirow{2}{*}{ Total } \\
\hline & & Male & Female & \\
\hline \multirow{3}{*}{ MPDS } & \multirow{2}{*}{ Yes } & 152 & 188 & 340 \\
\cline { 3 - 5 } & & $45.1 \%$ & $28.0 \%$ & $33.7 \%$ \\
\cline { 2 - 5 } & \multirow{2}{*}{ No } & 185 & 484 & 669 \\
\cline { 3 - 5 } & & $54.9 \%$ & $72.0 \%$ & $66.3 \%$ \\
\hline \multirow{2}{*}{ Total } & 337 & 672 & 1009 \\
\cline { 3 - 5 } & & $100.0 \%$ & $100.0 \%$ & $100.0 \%$ \\
\hline \multirow{2}{|c|}{}
\end{tabular}

\section{Table 14}

\begin{tabular}{|c|c|c|c|c|}
\hline \multicolumn{2}{|c|}{} & \multicolumn{2}{|c|}{ Gender } & \multirow{2}{*}{ Total } \\
\hline \multirow{3}{*}{ Osteoarthritis } & \multirow{2}{*}{ Yes } & 85 & 213 & 298 \\
\cline { 3 - 5 } & & $25.2 \%$ & $31.7 \%$ & $29.5 \%$ \\
\cline { 3 - 5 } & \multirow{2}{*}{ No } & 252 & 459 & 711 \\
\cline { 3 - 5 } & & $74.8 \%$ & $68.3 \%$ & $70.5 \%$ \\
\hline \multicolumn{2}{|c|}{ Total } & 337 & 672 & 1009 \\
\cline { 3 - 5 } & & $100.0 \%$ & $100.0 \%$ & $100.0 \%$ \\
\hline \multicolumn{2}{|c|}{} & \multicolumn{2}{|c}{ Female } & \\
\hline
\end{tabular}

\section{Table 15}

\begin{tabular}{|l|c|c|c|c|}
\hline \multicolumn{2}{|c|}{} & \multicolumn{2}{c|}{ Gender } & \multirow{2}{*}{ Total } \\
\hline \multirow{3}{*}{$\begin{array}{l}\text { Internal } \\
\text { Derangement }\end{array}$} & \multirow{2}{*}{ Yes } & 100 & 271 & 371 \\
\cline { 3 - 5 } & & $29.7 \%$ & $40.3 \%$ & $36.8 \%$ \\
\cline { 2 - 5 } & \multirow{2}{*}{ No } & 237 & 401 & 638 \\
\cline { 3 - 5 } & $70.3 \%$ & $59.7 \%$ & $63.2 \%$ \\
\hline \multicolumn{2}{|c|}{ Total } & 337 & 672 & 1009 \\
\cline { 3 - 5 } & $100.0 \%$ & $100.0 \%$ & $100.0 \%$ \\
\hline
\end{tabular}

The MPDS was more prevalent in $<18 \mathrm{yrs}$ of age a group (78.6\%) followed by 18-35yrs (72.2\%). And this association was statistically significant $(\mathrm{P}$ value $<0.001)$ (Table 16). The osteoarthritis is more prevalent in 51 to 65 yrs $(58 \%)$ age group followed by $>65 \mathrm{yrs}$ age group
$(47.4 \%)$. This association is statistically significant ( $\mathrm{P}$ value $<0.001$ ) (Table 17). The internal derangement is more common in 36 to $50 \mathrm{yrs}$ age group (52.9\%) and it was statistically significant ( $\mathrm{P}$ value $<0.001)$ (Table 18).

\section{Table 16}

\begin{tabular}{|c|c|c|c|c|c|c|c|}
\hline \multicolumn{2}{|c|}{} & \multicolumn{7}{|c|}{ Age Intervals } & \multirow{2}{*}{ Total } \\
\hline \multicolumn{2}{|c|}{} & $\begin{array}{c}\text { Below } \\
\mathbf{1 8 y r s}\end{array}$ & $\begin{array}{c}\mathbf{1 8} \text { to } \\
\mathbf{3 5 y r s}\end{array}$ & $\begin{array}{c}\text { 36 to } \\
\mathbf{5 0 y r s}\end{array}$ & $\begin{array}{c}\mathbf{5 1} \text { to } \\
\mathbf{6 5 y r s}\end{array}$ & $\begin{array}{c}\text { More than } \\
\text { 65yrs }\end{array}$ & \\
\hline \multirow{3}{*}{ MPDS } & \multirow{2}{*}{ Yes } & 33 & 294 & 13 & 0 & 0 & 340 \\
\cline { 2 - 8 } & $78.6 \%$ & $72.2 \%$ & $5.7 \%$ & $.0 \%$ & $.0 \%$ & $33.7 \%$ \\
\cline { 2 - 8 } & \multirow{2}{*}{ No } & 9 & 113 & 214 & 219 & 114 & 669 \\
\cline { 3 - 8 } & $21.4 \%$ & $27.8 \%$ & $94.3 \%$ & $100.0 \%$ & $100.0 \%$ & $66.3 \%$ \\
\hline \multirow{2}{*}{ Total } & 42 & 407 & 227 & 219 & 114 & 1009 \\
\cline { 2 - 8 } & $100.0 \%$ & $100.0 \%$ & $100.0 \%$ & $100.0 \%$ & $100.0 \%$ & $100.0 \%$ \\
\hline
\end{tabular}


Table 17

\begin{tabular}{|c|c|c|c|c|c|c|c|}
\hline & \multicolumn{5}{|c|}{ Age Intervals } & \multirow[t]{2}{*}{ Total } \\
\hline & & $\begin{array}{c}\text { Below } \\
\text { 18yrs }\end{array}$ & $\begin{array}{l}18 \text { to } \\
35 \text { yrs }\end{array}$ & $\begin{array}{l}36 \text { to } \\
50 \mathrm{yrs}\end{array}$ & $\begin{array}{l}51 \text { to } \\
65 y r s\end{array}$ & $\begin{array}{c}\text { More than } \\
65 y r s\end{array}$ & \\
\hline \multirow{4}{*}{ Osteoarthritis } & \multirow{2}{*}{ Yes } & 2 & 21 & 94 & 127 & 54 & 298 \\
\hline & & $4.8 \%$ & $5.2 \%$ & $41.4 \%$ & $58.0 \%$ & $47.4 \%$ & $29.5 \%$ \\
\hline & \multirow{2}{*}{ No } & 40 & 386 & 133 & 92 & 60 & 711 \\
\hline & & $95.2 \%$ & $94.8 \%$ & $58.6 \%$ & $42.0 \%$ & $52.6 \%$ & $70.5 \%$ \\
\hline \multirow{2}{*}{\multicolumn{2}{|c|}{ Total }} & 42 & 407 & 227 & 219 & 114 & 1009 \\
\hline & & $100.0 \%$ & $100.0 \%$ & $100.0 \%$ & $100.0 \%$ & $100.0 \%$ & $100.0 \%$ \\
\hline
\end{tabular}

Table 18

\begin{tabular}{|c|c|c|c|c|c|c|c|}
\hline & \multicolumn{5}{|c|}{ Age Intervals } & \multirow[t]{2}{*}{ Total } \\
\hline & & $\begin{array}{l}\text { Below } \\
\text { 18yrs }\end{array}$ & $\begin{array}{l}18 \text { to } \\
35 y r s\end{array}$ & $\begin{array}{l}36 \text { to } \\
50 \mathrm{yrs}\end{array}$ & $\begin{array}{l}51 \text { to } \\
65 y r s\end{array}$ & $\begin{array}{c}\text { More than } \\
65 y r s\end{array}$ & \\
\hline \multirow{4}{*}{$\begin{array}{l}\text { Internal } \\
\text { Derangement }\end{array}$} & \multirow{2}{*}{ Yes } & 7 & 92 & 120 & 92 & 60 & 371 \\
\hline & & $16.7 \%$ & $22.6 \%$ & $52.9 \%$ & $42.0 \%$ & $52.6 \%$ & $36.8 \%$ \\
\hline & \multirow{2}{*}{ No } & 35 & 315 & 107 & 127 & 54 & 638 \\
\hline & & $83.3 \%$ & $77.4 \%$ & $47.1 \%$ & $58.0 \%$ & $47.4 \%$ & $63.2 \%$ \\
\hline \multirow{2}{*}{\multicolumn{2}{|c|}{ Total }} & 42 & 407 & 227 & 219 & 114 & 1009 \\
\hline & & $100.0 \%$ & $100.0 \%$ & $100.0 \%$ & $100.0 \%$ & $100.0 \%$ & $100.0 \%$ \\
\hline
\end{tabular}

\section{Discussion}

TMDs are the principle cause for chronic facial pain. The term TMD has been epitomized as a cluster of disorders defined by pain in the preauricular area, TMJ or the masticator muscles limitation or deviations in mandibular range of motion and clicking sound in the TMJ during mandibular function. The temporomandibular disorders are not pertained to growth or developmental disorders, systemic diseases and macrotrauma ${ }^{11}$. Schwartz ${ }^{12}$ defined the temporomandibular pain dysfunction syndrome primarily as a symptom complex which is seen in young or middle aged adults. Some of the signs are tenderness of the joint, dull pain which upsurgeon mouth opening, muscle tenderness, referred pain to the angle of mandible, muscles of the neck, limited mouth opening, deviation on mouth opening and joint sounds characterized by crepitus and clicking.

Emotional tension and occlusion play an unambiguous etiological role to produce muscle spasm which provokes these symptoms. Several opinions are conveyed in the literature whether occlusion is the cause or the result of the dysfunction or vice versa. ${ }^{13}$ Feteihet $\mathrm{al}^{14}$ revealed TMD prevalence of $21.3 \%$ in 385 adolescents aged between 12 and 16 years. Thilanderet $\mathrm{al}^{15}$ showed the prevalence was $20 \%$ and $25 \%$ among adolescents. A meta-analysis published in 1993 on 51 random samples and selected TMD prevalence studies conducted from 1974 to 1991 showed clinically determined TMD frequency in the range of $0-93 \%$ (an average of 44\%) and TMD prevalence in the range of 6$93 \%$ (an average of $30 \%$ ) based on the information obtained from questionnaires. ${ }^{16}$ Matsuka et al ${ }^{17}$ stated that the prevalence of these symptoms was $24 \%$ and was thus higher than in other studies. A German study ${ }^{18}$ reported that 20-59-year-old women were significantly more frequently aware of joint sounds than men.Agerberget $\mathrm{al}^{19}$ reported that the overall prevalence of clicking detected by clinical examination was $17 \%$ in men and $27 \%$ in women. A study was conducted in the county of Stockholm, Sweden on persons aged 18-65 years and it was concluded that clicking sound is present in $21 \%$ males and $28 \%$ females however crepitus was detected in $26 \%$ men and $40 \%$ women..$^{20}$ Gesch et al ${ }^{18}$ reported that clicking and crepitus is present in $24.9 \%$ of the subjects with women having clicking sounds significantly more frequent than men almost twice (Female(31.7\%) vs. male(17.9\%)). Tervonen et $\mathrm{al}^{21}$ reported that the rate of occurrence of clicking sound and crepitus was $20 \%$ however they did not described gender or age dependent differences. However a study conducted in Danish population concluded that the rate of occurrence of crepitus and clicking joint was $15.4 \%$.The predilection is $19 \%$ for female and $12.2 \%$ for male. ${ }^{22}$ A study conducted in Japanese population ${ }^{17}$ reported a higher prevalence of clicking (46\%) and crepitation (19\%) in their study sample.

Gesch et $\mathrm{al}^{18}$ observed that the prevalence of masticatory muscle tenderness was $12 \%$ whereas on contrary the prevalence rates of masticatory muscle tenderness reported in a Swedish study conducted by Salonen et $\mathrm{al}^{23}$ and Japanese ${ }^{17}$ study were $19 \%$ and $21 \%$ respectively. Muthukrishnanet $\mathrm{al}^{1}$ reported that the joint tenderness was present in $3.2 \%$ of the population and was maximum in the age group of $>50$ years. Females showed a higher prevalence of joint tenderness (4.8\%) when compared to males (2.4\%) with a high significance $(P<0.001)$.As part of the national health interview survey hitch was administered by telephone 
to a large representative sample of the US population, joint tenderness was reported in $7 \%$ of women and $3.5 \%$ of men. ${ }^{24}$ Agerberg et $\mathrm{al}^{19}$ also reported that joint tenderness to range from $0.5 \%$ to $7.9 \%$ with an overall rate of $2.5 \%$ for men and $4.9 \%$ for women and the highest rate of joint pain were found in the oldest age group. Muthukrishnanet $\mathrm{al}^{1}$ also stated that pain on mouth opening was evident in $2.3 \%$ of study population. $3.5 \%$ of the study population in the age group of $>50$ years experienced maximum pain on mouth opening. Females encountered more pain on mouth opening (3.6\%) than men $(1.7 \%)$ and it was statistically significant. Gesch et $\mathrm{al}^{18}$ reported pain upon mouth opening in $1.2 \%$ of the subjects and this symptom was more frequent among women than men in the age group of $40-59$ years $(2.1 \%$ vs. $0.4 \%)$.Salonen et $\mathrm{al}^{23}$ also reported the prevalence of pain on mouth opening to be $3 \%$ and $0.7 \%$ in females and males respectively in their study sample. Muthukrishnanet $\mathrm{al}^{1}$ also stated that deviation of mandible on mouth opening was reported by $42.1 \%$ of individuals. $75.2 \%$ of individuals in the age group of $>50$ years reported deviation of mandible on mouth opening more frequently. Deviation on mouth opening was prevalent in $62.3 \%$ of the subjects in $31-50$ years age group with the least rate being reported in those belonging to $18-30$ years age group $(18 \%)(P$ < $0.001)$.Females showed a slightly higher prevalence of mandibular deviation (44.9\%) than males $(40.5 \%)(P=$ 0.020). The MPDS was more prevalent in male $(45.1 \%)$ than female $(28 \%)$. However the higher percentage of Osteoarthritis was found in females (31.7\%) than male $(\mathrm{P}<0.05)$. Females have more prevalence for internal derangement $(40.3 \%)$ than male $(\mathrm{P}<0.05)$. On comparing in age groups, maximum cases of MPDS were found in $<18$ years $(78.6 \%)$ group followed by 18 35 years $(72.2 \%)$ and so on. So it was concluded as age increases the prevalence of MPDS decreases $(\mathrm{P}<0.05)$.The maximum cases of osteoarthritis was found in 51-65 years (58\%) group followed by $>65$ years $(47.4 \%)$ group. So as the age progresses prevalence of osteoarthritis is increases $(\mathrm{P}<0.05)$. Mostly old aged individual suffers from this disorder. The internal derangement was most commonly found in $36-50$ years $(52.9 \%)$ group followed by $>65$ years $(52.6 \%)$.So as the age progresses prevalence of internal derangement increases too. Statistically this association was significant $(\mathrm{P}<0.05)$.Clicking sound was more prevalent in males $(47.2 \%)$ with evident click. The crepitus $(26.6 \%)$ and joint tenderness $(8.1 \%)$ was more common in females than males. On observing the association of gender with deviation of mandible on opening, it was found that, the higher percentage was obtained in males than females $(47.2 \%>37.8 \%)$. However pain on mouth opening $(7.1 \%)$ was more common with females than males. When compared in age groups, the clicking sound was most common in $<18$ years $(62.5 \%)$ age group followed by 18 -35years
(55.6\%) age group. So it is depicted that clicking sound is generally found in 10-35 years of life of an individual. Crepitus was more common in $>65$ years $(58.6 \%)$ age group followed by 51-65 years of age group $(50.9 \%)$. So it was concluded that crepitus was felt more at $5^{\text {th }} 6^{\text {th }}$ decade of life. Maximum cases of joint tenderness were found in age of 51-65 years (7.1\%) age group. Deviation of mandible was most prevalent in 51-65 years (49.4\%) age group followed by $36-50$ years $(41.5 \%)$. However maximum cases of pain on mouth opening was found in $<18$ years $(37.5 \%)$ age group. It was also concluded that $28 \%$ of the subjects who had crepitus and $25.1 \%$ of the subjects who had clicking sound in temporomandibular joint were also having deviation of mandible on mouth opening.

\section{Conclusion}

The results and outcomes of this study en-surfaced the fact that there was a coalition between signs and symptoms of TMD and para-functional habits. The outcomes of present study may serves as the milestone for the researchers and clinician to carry out screening of signs and symptoms based on RDC/TMD criteria and send the affected patients for further treatment.

\section{References}

1. Muthukrishnan A, Sekar GS. Prevalence of temporomandibular disorders in Chennai population. Journal of Ind Acad of Oral Med Radiol 2015;27(4):508.

2. Mutlu N, Herken H, Güray E, Öz F, Kalayci A. Evaluation of the prevalence of temporomandibular joint disorder syndrome in dental school students with psychometric analysis. Turkish J Med Sci 8;32(4):345-50.

3. Schmitter M, Rammelsberg P, Hassel A. The prevalence of signs and symptoms of temporomandibular disorders in very old subjects. J Oral rehabil 2005;32(7):467-73.

4. Modi P, Shaikh SS, Munday A. A cross sectional study of prevalence of Temporomandicular joints in university students. Int J Sci Res Pub 2012;2(9):1-3.

5. Nilner M, Lassing SA. Prevalence of functional disturbances and diseases of the stomatognathic system in 7-14 year olds. Swedish Dent J 1981;5(5-6):173-87.

6. Nassif NJ, Hilsen KL. Screening for temporomandibular disorders: History and clinical examination. J Prostho 1992;1(1):42-6.

7. Cooper BC, Kleinberg I. Examination of a large patient population for the presence of symptoms and signs of temporomandibular disorders. Cranio $® 2007 ; 25(2): 114-$ 26.

8. Okeson JP. Management of Temporomandibular Disorders and occlusion (ed 3).St. Louis.

9. Hegde S, Mahadev R, Ganapathy KS, Sujatha D, Patil BA. Prevalence of signs and symptoms of temporomandibular joint disorders in dental students. JIAOMR 2011;23(3):S316-9.

10. Gopal SK, Shankar R, Vardhan BH. Prevalence of temporo-mandibular joint disorders in symptomatic and asymptomatic patients: A cross-sectional study. Int $J$ Adv Health Sci 2014;1(6):14-20.

11. Casanova-Rosado JF, Medina-Solís CE, VallejosSánchez AA, Casanova-Rosado AJ, Hernández-Prado B, Ávila- Burgos L. Prevalence and associated factors for temporomandibular disorders in a group of Mexican 
adolescents and youth adults. Clin Oral Invest 2006;10:42-9.

12. Schwartz LL. A Temporomandibular joint pain dysfunction syndrome. J Chronic Dis 1956;3:284-293. doi:10.1016/00219681(56)901230.

13. Shetty R. Prevalence of signs of temporomandibular joint dysfunction in asymptomatic edentulous subjects: A cross-sectional study. The Journal of Ind Prostho Society 2010;10(2):96-101.

14. Feteih RM. Signs and symptoms of temporomandibular disorders and oral parafunctions in urban Saudi Arabian adolescents: A research report. Head Face Med 2006;2:25

15. Thilander B, Rubio G, Pena L, de Mayorga C. Prevalence of temporomandibular dysfunction and its association with malocclusion in children and adolescents: An epidemiologic study related to specified stages of dental development. Angle Orthod 2002;72:146-54.

16. De Kanter RJ, Truin GJ, Burgersdijk RC, Van't Hof MA, Battistuzzi PG, Kalsbeek H, et al. Prevalence in the Dutch adult population and a meta-analysis of signs and symptoms of temporomandibular disorder. J Dent Res 1993;72:1509-18.

17. Matsuka Y, Yatani H, Kuboki T, Yamashita A. Temporomandibular disorders in the adult population of Okayama City, Japan. Cranio 1996;14:158-62.

18. Gesch D, Bernhardt O, Alte D, Schwahn C, Kocher T, John Uet al. Prevalence of signs and symptoms of temporomandibular disorders in an urban and rural German population: Results of a population-based Study ofHealth in Pomerania. Quintessence Int 2004;35:143-50.

19. Agerberg G, Bergenholtz A. Craniomandibular disorders in adult population of West Bothnia, Sweden. Acta Odontol Scand 1989;47:129-40.

20. Agerberg G, Inkapööl I. Craniomandibular disorders in an urban Swedish population. J Cranomandib Disord 1990;4:154-64.

21. Tervonen T, Knuuttila M. Prevalence of signs and symptoms of mandibular dysfunction among adults aged 25, 35,50, and 65 years in Ostrobothnia, Finland. J Oral Rehabil 1988;15:455-63.

22. Goulet JP, Lavigne GI, Lund JP. Jaw pain prevalence among French-speaking Canadians and related symptoms of temporomandibular disorders. I Dent Res 1995;74:1738-44.

23. Salonen L, Helldén L, Carlsson GE. Prevalence of signs and symptoms of dysfunction in the masticatory system: An epidemiology study in an adult Swedish population. $J$ Craniomandib Disord 1990;4:241-50.

24. Lipton IA, Ship JA, Larach-Robinson D. Estimated prevalence and distribution of reported orofacial pain in the United States. I Am Dent Assoc 1993;124:115-21. 